\title{
The Influence of Sustainable Development Module on the Values and Beliefs of First-Year Students in Undergraduate Engineering Education
}

\section{Radhika Amashi ${ }^{1}$, Dr. Gopalkrishna Joshi ${ }^{2}$, Dr. Rohit Kandakatla ${ }^{3}$}

${ }^{1}$ Centre for Engineering Education Research, KLE Technological University, Hubballi

${ }^{2}$ Executive Director, Karnataka State Higher Education Council, Bangalore

${ }^{3}$ Department of Electronics and Communication, KGR College of Engineering, Hyderabad

${ }^{1}$ radhika.amashi@kletech.ac.in

${ }^{2}$ ghjoshi@kshec.ac.in

\section{${ }^{3}$ rohit.kanadakatla@kgr.ac.in}

Abstract: Education for Sustainable Development (SD) has become vital in the field of engineering education because there is a need that engineers of the $21^{\text {st }}$ century should not only build technologies and solutions that meet human needs but are also expected to situate their professional practice in the context of society and the environment. Currently, most of the literature right now is focused on integrating the concept of SD in engineering education either at the first or higher semesters of the undergraduate program. To our knowledge, these studies discuss the process of integration, the impact of integration on student learning outcomes, desired competencies for SD, different teaching and learning strategies, and understanding student perception about SD. However, this study contributes to the literature by examining how this integration is influencing student's knowledge, values, and behaviors in the first year of engineering as the outcome of integration. In this paper, we examine one such effort and try to investigate the impact of an SD module that was introduced to first-year engineering students as part of an engineering exploration course. Embedded mixed methods were used to understand the impact of introducing the SD module on student's knowledge, beliefs, and values. From the results, we observe that there was no significant change in knowledge when analyzed quantitatively however qualitative analysis showed that the module had influenced students to transition from basic awareness about SD to accepting or committing to SD principles and finally reporting to take actions towards sustainable living and development.

\section{Corresponding Author}

Radhika Amashi, Centre for Engineering Education Research,

KLE Technological University. Hubballi

radhika.amashi@kletech.ac.in

Keywords: Education for Sustainable Development, First-Year Engineering Students, Values, Beliefs, and Knowledge.

\section{Introduction}

Engineering and technology are getting increasingly socialized and engineering solutions have to be mindful of nature and the environment. Today's interconnected global challenges demand responses that are rooted in the spirit of our collective humanity. Sustainability is becoming an integral part of education at all levels. There is now a growing international recognition of Education for Sustainable Development (ESD) as an integral element of quality education and a key enabler for sustainable development (UNESCO Roadmap, 2014). Engineers of the $21^{\text {st }}$ century are required to know beyond the disciplines of engineering and situate their professional practice in the context of society and the environment. Engineers should not only build technologies and solutions but are also expected to analyze the positive and negative impacts of them concerning society and the environment (Lehman et al., 2008). Accordingly, there is a need to educate engineering students on sustainability. We see that there are two approaches to introducing sustainability education in the undergraduate engineering curriculum: Vertical integration and Horizontal integration. Vertical integration is about adding a whole new course on sustainability to the curriculum (Watson et al., 2013),(Segalàs et al., 2008) and horizontal integration involves adding sustainabilityrelated topics into an existing course or designing a specialist sustainability degree program (Kemppainen et al., 2007),(Bielefeldt and Angela R, 2011), (Lozano et al., 2014),(Lu et al., 2015),(Rose et al., 2015b).The ideal point of integration of sustainability to create its impact and maximize the reach at the first-year engineering level as it begins with the combination of different disciplines (Rose et al., 2015a). Prior efforts by engineering educators on integrating sustainability topics at the first-year level have resulted in students being mindful of sustainability while problem-solving. Teaching about SD at firstyear engineering has also been seen to promote multi-disciplinary solutions to problems related to sustainability in higher semesters of their engineering as well as in their professional career.

In this paper, we examine one such effort and try to investigate the impact of an SD module that was introduced to first-year engineering students as part of an engineering exploration course. We aim to study the impact of the module on the student's knowledge, values, and behavior and propose the following objectives:

1. Evaluating first-year student's knowledge of sustainable development before and after the delivery of the SD module.

2 . Identify changes in student`s values and beliefs after completing the SD module.

In the further sections of the paper, we provide an overview of the past efforts carried out to introduce students to sustainable development followed by an overview of the qualitative methods used to design the research study, collect, and analyze the data. Results from the thematic analysis are later presented along with relevant quotes from the student interview.

\section{Literature Review}

\section{A. Introduction to Sustainable Development}

The idea of sustainable development first emerged in the year 1987 in response to the world`s social and environmental problems with globalization. The widely accepted definition for the term "Sustainable Development" is "Development that meets the needs of the present without compromising the ability of future generations to meet their own needs" from Brundtland Commission Report published under the title "Our Common Future" (UNESCO). This definition highlights the importance of social and economic development and recognizing the relationship between the economy and environment and accepting the limitations set by the carrying capacity of the environment (Kagawa and Fumiyo, 2007). The concept of SD appears at the crossroads of social responsibility, economic development, and environmental protection, which are considered as pillars of SD. Environmental protection is outlined as the safeguarding of natural resources for the long-term without harming the ecosystem and social responsibility is stated as agreement and cooperation between communities and regions. Economic development is described as assuring the quality of life in terms of both health and wealth from an individual and societal perspective. The concept of SD has a variety of interpretations as it is dynamic (Berglund et al., 2014). To decide on the ultimate definition of sustainability for engineering education is out of the scope of this paper. Therefore, we consider the Brundtland commission definition as a point of departure to carry out this study. B. Education for Sustainable Development

Agenda 21, the outcome of the United Nations Conference on Environment and Development held in Rio de Janeiro in the year 1992 highlighted the importance of education for sustainable development, where not only the environment but also social and economic aspects were also taken into account for sustainable future (Berglund et al. 2014). Further, UNGA (United Nations General Assembly) designated UNESCO to lead the United Nations DESD (Decade for Sustainable Development) from 2005 to 2014 with the focus on to reorient education to learn the values, behaviors, and lifestyles needed for a sustainable future, positive societal transformation and ensure everyone has the opportunity to learn and benefit. ESD is defined as "a process of learning how to 
make decisions that consider the long-term future of the economy, ecology, and equity of all communities" (Kagawa and Fumiyo, 2007), (Berglund et al., 2014), stated that ESD is an approach to teaching and learning and its important aspect is the combination of cognitive and affective domains which include knowledge, abilities, values, and attitudes.

C. Importance of ESD in Engineering Education

The importance of education for sustainable development was brought to light through many conferences and meetings such as the Stockholm declaration, Chapter 36 of the agenda 21 in Rio, The Earth Charter Declaration, Declaration UBUNTU, and United Nations Decade of Education for Sustainable Development (20052014). The guidelines developed as the outcome of these meetings have been followed by various authors to integrate SD in the engineering curriculum (Segalàs et al., 2008) (Azapagic et al., 2005) mentions that the engineering profession has a vital role in improving the quality of life for everyone and thus highlights the importance of considering challenges of sustainable development into the curriculum. Higher education institutions are responsible to educate students with the necessary technical knowledge, moral vision, and to assure the quality of life for next-generation(Segalàs et al., 2008). (Michalos et al., 2005) in his works have shown that people`s behavior is influenced by their values, attitudes, knowledge, and creativity. Their ability to solve problems can be influenced by their actions and behavior.

D. Efforts were taken by engineering educators to integrate SD into the undergraduate curriculum

There have been several efforts to introduce sustainability education in the engineering curriculum. (Kemppainen et al., 2007) describes the integration of sustainability activities into two of the common first-year engineering courses (ENG1101 and ENG1102) at Michigan Technological University which deal with ethics, technical communication, spreadsheets, engineering problem solving, and design, 3-D modeling and visualization, and computer programming. The goal of the class module was to create awareness of sustainability among students and was designed to incorporate sustainability into the design process and encourage students to develop innovative solutions. The solutions provided by students should explain how their solutions were socially acceptable, environmentally friendly, and economically feasible. (Bielefeldt and Angela R, 2011) have described their experiment in which a module was added into two first year, 1-credit introductory courses (Civil and Environmental Engineering). The results showed that there was an improvement in knowledge and a positive attitude towards sustainability and introducing the concept of sustainability at early phases of education had impacted student's conception.

At Georgia Institute of Technology, a module on sustainability was introduced into the senior-level, civil, and environmental engineering design course. This study uses concept maps and surveys to study the impact of a learning-cycle-based module on a student's conceptual understanding of sustainability. The results of this study support that students demonstrated a balanced understanding of sustainability. Further, the module implementation provided empirically tested learning materials and assessment methods that could be adopted for other engineering disciplines(Watson et al., 2016). As reported by $\mathrm{Lu}$ (Lu et al., 2015) in their work, sustainability is introduced into an introduction to environmental engineering courses, to create awareness among civil and environmental engineering students about the sustainability of water, air, land, and its impact on the ecosystem. The effectiveness of the integration was evaluated using the formative and summative assessment questions.

The awareness of environmental sustainability is seen to be gradually improved over time and students have also become more receptive to knowledge on the environment. The work by (Rose et al., 2015b) focuses on the process of curriculum renewal to embed sustainability into first-year engineering education and is described using a case study. The use of a web-based portal for delivering content to students has been highlighted. The results show that the student`s self-report knowledge about sustainability has improved after taking the course. The University of Surrey employed a "three-tier" approach to teaching sustainability concepts in which the first tier is dedicated to introducing students to the concept of sustainability through lectures and tutorials. In the second tier, students were exposed to practical case studies to enable them to apply sustainability concepts and identify solutions. The third tier included the integration of sustainability thinking into the overall curriculum. The authors stated that this approach helps in promoting learning outcomes that enable students to establish a connection between engineering and SD (Azapagic et al., 2005).

(Fini et al. 2018) developed an intervention in which a group of students works on transportation-related activities. The activity is designed such that they work on a specific problem by collecting a list of ideas and then validating the feasibility of ideas. The activity was followed by a lecture about topics related to sustainable transportation. The results show that the intervention improved student's ease of learning the concepts of sustainability-related to transportation. Therefore, the pedagogy practiced in delivering the course plays an important role in student learning and the effectiveness of the course. For sustainability, courses that use active, community-oriented, and constructive learning pedagogical approaches such as project-based learning, case studies, and roleplay has shown to be effective in increasing the student's knowledge. For introducing the concept of sustainability, lecturing is also considered to be effective(Segalàs et al., 2010). The use of active and collaborative learning pedagogies has however enabled students to gain a holistic view of the engineering profession and develop multidisciplinary skills (Baligar et al., 2018).

\section{Methodology}

This section of the paper includes the context of the study, the research question that we intend to answer through this study, followed by the method used to conduct the study. It also describes the data collection procedure, participants chosen for this study, and the process of data analysis.

A. Context of the study

A small effort is made to introduce the concept of sustainability into first-year engineering curricula through the Engineering exploration course at KLE Technological University India. "Engineering Exploration" is a three-credit core course at the firstyear level with the following course outcomes:

- Explain the role of an Engineer as a problem solver.

- Apply multi-disciplinary skills to solve complex engineering problems.

- Build engineering systems using the engineering design process.

- Use the basics of project management in doing projects.

- Analyze engineering solutions from ethical perspectives.

- Analyze engineering solutions from sustainability perspectives.

The course has one module on sustainability with the following topic learning outcomes:

- Explain that the role of engineers is vital in sustainable engineering design

- Analyze an engineering situation based on the three pillars of sustainable development - People, Planet and Profit

- Select the engineered product based on the life cycle assessment

- Draw the inference out of carbon footprint calculations in his day to day life.

1) Sustainability Module: The goal of this module is to introduce the concept of sustainability and the role of engineers in sustainable development. The module is divided into two sessions each with 3 hours of duration. In the first session, students are introduced to sustainable development (SD) by brief history about SD and discussing the 3 main pillars- people, planet, and profit. The role of engineers while developing a product and the technological impact on the environment are addressed using the sustainability leadership matrix. The Life Cycle Assessment(LCA) tool is introduced to understand the impact of the product right from birth to death. The second session deals with the introduction of carbon footprint, its impact, and calculations of $\mathrm{CO} 2$ emission in his day to day life. Active and constructive learning pedagogical approach is used to deliver the module. The following are the activities in the module where a team of 2 students performs these activities. 
1. Discussion: To find more issues related to people, planet, and profit.

2. Case Study: To judge if the given example is sustainable or not. If not, How can we make it sustainable?

3. Construct LCA: Perform LCA for either steel door or wooden by going through the Tata Pravesh Brochure.

4. Calculation: Calculation of carbon footprint.

But due to the sudden occurrence of the COVID19 pandemic, the intervention was delivered through online mode and the delivery time was reduced to 1.5 hours without active and constructive learning pedagogy.

Most of the studies in the literature mentioned above discuss the process of integration, the impact of integration on student learning outcomes, desired competencies for SD, different teaching and learning strategies, and understanding student perception about SD. However, there are no studies that explicitly study and understand if the introduction to SD has resulted in a change in the beliefs and values of the students after the course. This study, therefore, contributes to the literature by examining how the integration of SD has influenced student's knowledge, value, and behaviors in the first year of engineering as the outcome of integration.

B. Research Question

How has the sustainability module influenced student`s knowledge beliefs and values in the first year of engineering?

\section{Methods}

The embedded mixed method is used to design the study and understand the influence of introducing an SD module in a firstyear engineering course on the students. As stated by (Creswell, J. W. 2002), in the embedded mixed-method the qualitative and quantitative data are collected simultaneously or sequentially in which one form of data plays a supportive role to the other form of data. We collected both quantitative data and qualitative data in parallel to help us address the research questions. Quantitative data was collected using the concept maps that students were asked to visualize and develop at the end of the course. Students were also interviewed through a semi-structured interview protocol to qualitatively understand the impact of the SD module on them. The Embedded mixed-methods approach was suitable for this research study as it would enable us to get in-detail insights about the values and behavioral changes in students after undergoing this module.

D. Participants

1) Sample for Quantitative Data: A total of 1052 first-year engineering students enrolled for the mandatory course "Engineering Exploration" for the academic year 2019-2020. At the institutional level, students were divided into 7 and 9 divisions during the first and second semesters. Each division consists of approximately 65 to 70 students. As a researcher and the course instructor of 2 sections of this course, the context of the study is limited to a sample of 140 students who were part of those 2 sections.

2) Sample for Qualitative Data: Purposive sampling is used to select a set of students for interviews. 7 students had a positive difference between pre-test and post-test scores and 7 students had a negative difference between pre-test and post-test scores so, a total of 14 students were chosen for the interview. However, one student did not agree to participate in the study.

E. Data Collection Procedure

1) Quantitative Data: The study began to identify what does "Understanding" means? Thus, understanding would mean that our engineering students should make progress towards thinking about sustainability in the way that engineering sustainability experts do. (Carew and Mitchell, 2002) The traditional tools to assess the student's knowledge/understanding are surveys, essays, and presentations however, the drawback of these tools is that they are restrictive in nature and lack of presentation skills can be mistaken as a lack of knowledge. We, therefore, used concept maps as a tool to collect quantitative data as it serves as a direct measure of student's knowledge or understanding in the domain (Watson and Barrella, 2017).

A concept map is a graph with nodes corresponding to important terms (concepts) in the domain and lines representing a relation between a pair of concepts (nodes). The labels (prepositions) on the line describe the relationship between the two concepts. A proposition is the smallest unit that can be used to judge the validity of the relationship between two concepts (Ruiz-Primo and Araceli).In our study, we focus on propositional knowledge (i.e. knowing that something is so) of sustainability. The interrelatedness between the concepts is important for the propositional knowledge to be usable (Ruiz-Primo and Araceli) and is the key feature that distinguishes between novice and expert-like thinking (Watson and Barrella, 2017)

Data collection procedure for concept map:

All 140 students in their respective divisions are trained on how to use the concept maps for a given topic through lecture slides covering some basic examples. During the pre-test, Students are asked to draw a concept map for the topic "Sustainability" on the paper and submit the soft-copy of the document through google forms. The sustainability module is delivered in online mode through the Microsoft Teams application. During the post-test students are asked to draw the concept map on the topic "Sustainability" on the paper and submit the soft-copy of the document through google forms. Purposive sampling is used to select the students for further study. Out of 140 students, 35 students were selected. All 140 concept maps were compared against each other and similar concept maps were ignored for the study. 35 concept maps were unique among themselves.

2) Qualitative Data: The knowledge parameter can be measured quantitatively however to get more insights about student's values and behavior a qualitative semi-structured interview was conducted. The results from the aualitative analvsis would also be used to triangulate the findin $\mathrm{Fig}$ 1: Initial Codes

A semi-structured interview was conducted individually with students comprising of direct questions and discussion. Table 1 shows the set of interview questions. The questions designed were validated by two experts and were pre-tested by conducting cognitive interviews with a group of students to void biases and variances among the respondents.

Data collection Procedure for Interview:

The consent form was prepared and sent to all 14 participants through their email address. Students were asked to read and sign the form only if they agree to the conditions specified. 13 students agreed and signed the forms. The interview was scheduled over the phone and was audio recorded. Each interview was scheduled based on the availability of students and the duration of the interview was 15 - 20 minutes. All the interviews after recording were transcribed by the researchers. After transcription, member checking was done by sending the interview transcripts to the students to verify the conversation during the interview.

Table 1: Semi-structured Interview Protocol

\begin{tabular}{|l|l|}
\hline Sl.no & Questions \\
\hline 1. & What does sustainable development mean to you? \\
\hline 2. & $\begin{array}{l}\text { How important it is for you to learn about sustainable } \\
\text { development? Why? }\end{array}$ \\
\hline 3. & $\begin{array}{l}\text { What is your role (as an engineer and citizen of the globe) } \\
\text { towards sustainable development? }\end{array}$ \\
\hline 4. & $\begin{array}{l}\text { Do you think engineers have additional responsibilities } \\
\text { towards sustainable development? If yes or no, why? }\end{array}$ \\
\hline 5. & How can you reduce your carbon footprint? \\
\hline 6. & $\begin{array}{l}\text { How can you convince others (in your community) to do the } \\
\text { same? }\end{array}$ \\
\hline 7. & $\begin{array}{l}\text { What is one learning from this module that could have } \\
\text { changed your outlook towards life? And why? }\end{array}$ \\
\hline 8. & $\begin{array}{l}\text { According to you, which one of the economic, social, or } \\
\text { environment will have the highest priority in sustainable } \\
\text { development? Why? }\end{array}$ \\
\hline
\end{tabular}

F. Data Analysis Procedure

1) Quantitative data analysis: Two aspects of the concept map are analyzed - structure and content.

Structure: Traditional method is used to analyze and score the structure of the map. This method scores the concept map using the below equation adapted from (Watson et al., 2016)

Total $=(\mathrm{NC}-\mathrm{NCL})+(\mathrm{HH}) * 5+(\mathrm{NCL}) * 10$.

$\mathrm{NC}$ represents the number of concepts included in the map. This parameter gives information about the knowledge breadth 


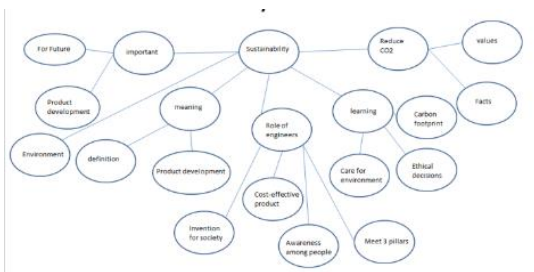

HH represents the highest hierarchy which is obtained by counting the maximum number of concepts in each hierarchy. This gives information about the knowledge depth.

NCL represents the cross-links obtained by counting the number of links between different hierarchies. This gives information about knowledge interconnectedness (Watson and Barrella, 2017)

Content: The knowledge content which gives information about the knowledge breadth is analyzed (Watson and Barrella, 2017) qualitatively. The 10 category taxonomy from the author (Watson et al., 2014) as shown in Table 2 is used to code the concept map data. The frequency of occurrences of each concept is a measure of knowledge breadth. Analyzing the structure of a concept map only gives information about the connectedness among different concepts without focusing on the content/concepts covered. Thus, content analysis is performed to study different concepts around sustainability that are perceived by students. A deductive approach is used to categorizing the concepts.

2) Qualitative data analysis: Thematic analyses were used to analyze the interview transcripts using the NVivo 10 tool. We followed the approach given by the author (Braun and Clarke, 2006) "Using thematic analysis in psychology" to conduct the thematic analysis. As discussed in the above section, the interview was conducted over the phone and was audio recorded. The audio records were manually transcribed to get familiar with the data.

Table 2: 10 Category Taxonomy

\begin{tabular}{|l|l|}
\hline Category & Examples \\
\hline Environment & $\begin{array}{l}\text { pollution, degradation, conservation (of } \\
\text { wildlife), biodiversity, ecological, footprint, } \\
\text { green/clean }\end{array}$ \\
\hline Resources & $\begin{array}{l}\text { renewable/non-renewable resources, lack of } \\
\text { materials, energy, food, water }\end{array}$ \\
\hline Social Impact & $\begin{array}{l}\text { quality of life, health, risk management, } \\
\text { shelter }\end{array}$ \\
\hline Values & $\begin{array}{l}\text { ethics, awareness, respect for traditions, } \\
\text { judgments about sustainability }\end{array}$ \\
\hline Future & $\begin{array}{l}\text { future generations, scenario analysis, } \\
\text { forecasting, backcasting }\end{array}$ \\
\hline Unbalance & $\begin{array}{l}\text { equity, fair distribution of goods, the fair use } \\
\text { of resources, needs of developing countries }\end{array}$ \\
\hline Technology & $\begin{array}{l}\text { best available technologies, industry, } \\
\text { efficiency, clean-technologies, the impact of } \\
\text { technology, technological efficiency }\end{array}$ \\
\hline Economy & $\begin{array}{l}\text { role of economy, fair trade, consumption, } \\
\text { economic efficiency }\end{array}$ \\
\hline Education & $\begin{array}{l}\text { role of education, rise of awareness, } \\
\text { educational institutions }\end{array}$ \\
\hline $\begin{array}{l}\text { Actors and } \\
\text { Stakeholders }\end{array}$ & $\begin{array}{l}\text { role of governments, rules, laws, international } \\
\text { agreements, politics, individuals, and society }\end{array}$ \\
\hline
\end{tabular}

The data was reread and cross-checked against the audio recordings. The data was initially open coded according to the 8 interview questions to understand each student's opinion and was read case by case to find repeated patterns

and the initial codes were generated as shown in Fig 1. All initial codes and the data within it were analyzed to find the relationship between different codes and as a result of the analysis, a set of themes emerged. The entire data was reread with the intent to find if any of the missing and repeated codes. Peer debriefing was used to review and validate each of the themes. Two of the colleagues were asked to check the suitability of the themes to the extracted content.

\section{Results}

A. Quantitative Results
1) Structure: As discussed in the above section, concept maps are scored using the traditional method and a paired sample t-test was conducted to compare the difference between the post-test and pretest scores. Table 3 describes the data considered for the study. The average total score of students $(n=34)$ in the pre-test is 49.21 with a standard deviation of 19.254. While the average of total scores in the post-test is 56.79 with a standard deviation of 18.650 .

Table 3: Descriptive Statistics

\begin{tabular}{|c|c|c|c|c|c|c|}
\hline & N & Min & Max & Mean & $\begin{array}{c}\text { Std } \\
\text { Dev }\end{array}$ & Variance \\
\hline Pre & 34 & 14 & 96 & 49.21 & 19.25 & 370.7 \\
\hline Post & 34 & 27 & 104 & 56.79 & 18.65 & 347.8 \\
\hline Valid N & 34 & \multicolumn{7}{|l}{} \\
\hline
\end{tabular}

Table 4 shows the Mean and Standard Deviation of the number of components, highest hierarchy, and the number of cross-links scores. The scores were calculated by 2 judges and Krippendorff's alpha is used to measure the inter-rater reliability of the judge's scores. The kalpha value obtained is kalpha $=0.085$. which is reliable.The results show that the significant difference in the pretest total scores $(\mathrm{M}=49.21, \mathrm{SD}=19.25)$ and post-test total scores $(\mathrm{M}=56.79, \mathrm{SD}=18.65) ; \mathrm{t}(33)=2.148, \mathrm{p}=0.039(\mathrm{p}<0.05)$ was less. Also, there was a significant difference observed in the $\mathrm{NC}$ and $\mathrm{HH}$ components of test scores at $\mathrm{p}<0.05$. NC represents the number of concepts mentioned by students and $\mathrm{HH}$ represents the highest hierarchy.

They represent the knowledge breadth and depth respectively. These two parameters show that students represented a small number of concepts related to SD. However, there was no significant improvement in the CL components of pre-test and posttest scores $(p>0.05)$. The $\mathrm{CL}$ represents the number of cross-links in the concept maps which indicates that students have not been able to establish a relationship between different concepts.

Table 4: Results of Paired Sample t-test

\begin{tabular}{|c|c|c|c|c|}
\hline $\begin{array}{c}\text { Score } \\
(\mathbf{n = 3 4})\end{array}$ & $\begin{array}{c}\text { Pre-test } \\
\text { Mean(SD) }\end{array}$ & $\begin{array}{c}\text { Post-test } \\
\text { Mean(SD) }\end{array}$ & $\mathbf{t}(33)$ & $\begin{array}{c}\text { P- } \\
\text { value }\end{array}$ \\
\hline NC & $20.15(9.95)$ & $23.59(9.47)$ & 2.044 & 0.049 \\
\hline HH & $3.74(1.5)$ & $4.35(1.64)$ & 2.67 & 0.012 \\
\hline CL & $1.15(1.43)$ & $1.27(1.47)$ & 0.301 & 0.766 \\
\hline Total & $49.21(19.25)$ & $56.79(18.65)$ & 2.148 & 0.039 \\
\hline
\end{tabular}

2) Content: The content within each concept map was coded to the predefined categories and as the result of coding the below graph represents the frequency of category used by students. From Fig 2 it is observed that the majority of students reported the environmental and social aspects of sustainable development.

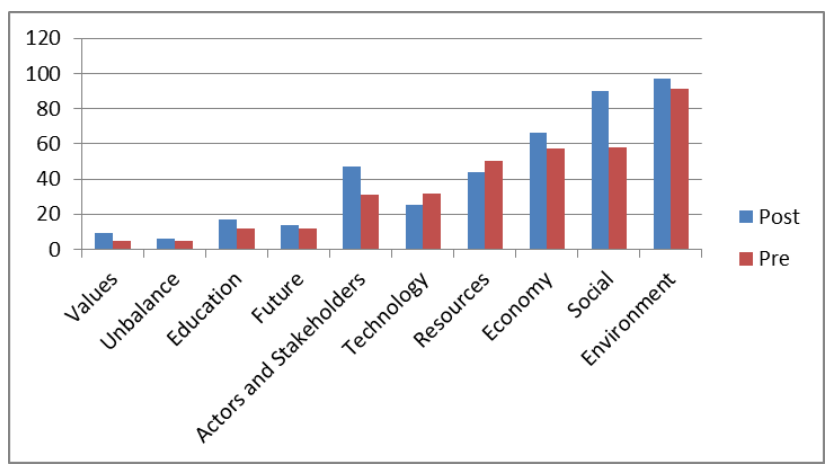

Fig 2: Distribution of contents based on category

B. Qualitative Results

As the results of thematic analysis, a set of 5 themes emerged from the data. These themes represent the values and beliefs of students after the SD module. Each theme is described with suitable quotes from the interview transcripts

Theme 1: Students expressed concern for the future generation. Students through the interviews were seen to respect and care for future generations. Students positioned themselves as present generation and were mindful about how their actions would impact future generations: "it is made aware that how important it is to think about the future generation. Because the rate at which we are using the resources they will not have any resources left for their 
use so". From the responses of the students, it is observed that the definition for Sustainable Development given by the Brundtland Commission -"development which meets the needs of current generations without compromising the ability of future generations to meet their own needs" had a lasting impact on students: "It is important because as a student and as a youth of India, it is our responsibility to save the environment and make it useful for our future generation". Students perceived the importance of individual responsibility for caring for the needs of future generation: "As a youth of this country, we have to know about sustainable development because we are the ones who are going to train the minds of the whole world in the coming era so it is very important as a part of our duty to do that. As future engineers, it is our responsibility to create and bring changes into the world that will lead us to a sustainable future"

Theme 2: Students started to care for the environment and commit to sustainable development.

The focus of student's views on Sustainable Development was observed to be more aligned with the environment, which is consistent with the literature. Students had developed a concern and care towards the environment and one reason for this could be the topic environment, being more common and is easily relatable to sustainable development. The second reason could the content of the intervention which is more aligned towards prioritizing the environment. One of the students said: "Buying vegetables from local vendors will impact the environment as transportation causes carbon emission which can be avoided by buying vegetables from local farmers"; "Completely stop using plastics, as it contributes a major part of carbon footprint, the noticeable fact is that even plastic recycling plants also emit carbon." This shows that the focus is more on the environment. While another student focused on both environment and society: "Development of human goals without harming the environment and needs of society to be fulfilled", few students expressed the sense of responsibility of committing to achieve sustainable development: "Let us take care that it is socially environmentally and economically good to all others. Not affecting the environment in the wrong" and "as an engineer, we are product makers so we should make less polluting products"

Theme 3: Students believed in a democratic approach to achieve sustainable development

This theme highlights the belief system where most of the students think that contribution or role of every individual is important for achieving sustainable development. One of the students said: "Everyone is considered to have an equal role in sustainable development. All professions are equally responsible for this development. Only one cannot change the present as strength lies in unity. Oneness comes when everyone joins their hands together". While another student mentioned: "Many people think that their lone contribution is not going to help the world when there are so many people. This mentality is responsible for all the things that are happening around, so it has to be changed. I would like to take is whatever the things are thought I do it as it is my responsibility without thinking what others think about it." Though the statements here are contradicting, student's intention about bringing in change through the people was highlighted. The sense of collaboration with people to bring in change was observed as a student said: "Everyone is equally responsible for sustainable development. If engineers design a car and if its efficiency is good to say mileage efficiency and if you have a neighbor who travels with you to the same place then we both can carpool"

Theme 4: Students trusted engineers to improve society through technology

The perception of using technology to improve society and the sense of professional responsibility is developed in students: "Engineers are playing an important role in our society as they are building new things now and then through technology to bring up a new society". From the statements made by students, it is clear that they perceive engineers as "Problem Solvers". Having this value embedded in students will enable them to build their further academic projects from a sustainability perspective: "most of the devices that every citizen uses in their everyday life are built by engineers and we have to make sure that whenever a product gets manufactured, it is meeting the needs of the people as well as not be harmful to the environment". These opinions have arisen due to the concept of the role of engineers that is covered in the intervention. Tools like Sustainable Leadership matrix which is a 2D matrix of Technological impact on environment versus affluence. It helps developers decide the position of the product within the matrix: "The role of engineers is to develop new technology which will give comforts to the people and at the same time it will not affect the planet."

Theme 5: Behavioural changes were observed among students towards sustainable living

All themes from 1 to 4 describe the student's values and beliefs while the $5^{\text {th }}$ theme describes the behavioral changes

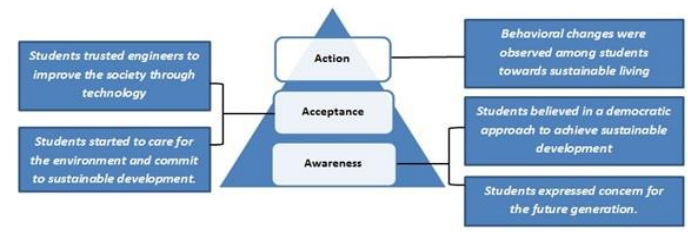

inf

Fig 3: AAA framework aligned with the themes

I used to use

$A C$ and was not aware of carbon footprint, so I used to use the vehicle to go to nearby places. I was not aware of sustainable development. I was not aware of sustainable development. After knowing the carbon footprint, I became conscious of the same and have told my parents about it too". Introducing the concept of carbon footprint had resulted in positive behavioral changes as seen in most of the student's interviews: "I use a bicycle to get some groceries for home from the nearby shops. I use public transport to travel to college from Dharwad" and "After this module, I have started to do this. I have kept a plant in my room. I feel sad and horrified when I see people use electricity unnecessarily. There are so many people in our society who do not get sufficient electricity to use, we have to imagine ourselves in their place and think about using electricity wisely", and "Buying eco-friendly products. While traveling to college choose public transport. Yes, I do travel to college by public transport".

\section{Discussion}

As we now have the results, we proceed with a discussion connecting to the research question. It is observed from the quantitative results that the majority of students represented the environmental concepts and related it to the SD in their concept maps and there was no significant change from the knowledge aspect of sustainable development. One possible reason for this is that the process of the data collection was done virtually without proctoring due to the unexpected COVID19 pandemic and there were no credits allotted for this activity. So this is one limitation of the study, where students may not have represented their knowledge to the best of their ability. However, the results from the qualitative analysis showed that the students did understand the concept of sustainable development indicating the three pillars of sustainable development and their role as engineers and as the citizen in attaining sustainability. From the five themes that emerged from the qualitative data analysis, the second theme conformed to the quantitative results which show that the focus of students was more towards the environment. We also see that students mention the engineers and individuals as the stakeholders for the sustainable development in the quantitative results which matches theme 3 and theme 4 in qualitative results. All of the themes 1 to 4 show the students perceive that sustainable development is important and can bring in change through individual contribution and collaboration. The next section describes the AAA model and the pragmatic implications of the results

A. Becoming mindful of sustainable living and development through Awareness Acceptance Action (AAA) framework It is also observed from the qualitative analysis that students underwent the process of awareness, acceptance, and action to become completely mindful of sustainable development and living. As shown in the below figure, theme 1 and 3 describe the awareness among students; theme 2 and 4 describe the acceptance and finally, theme 5 describe the actions for attaining sustainability. The AAA 
model is derived from Neil Abell and Scott Edward Rutledge's works (Rutledge 2005, Abell 2009) which is based on the principles of mindfulness. Awareness has two components. First is "looking deeply" which involves "noticing feelings, thoughts, and associations". The second component is "listening well" which involves "paying undistracted attention to a set of cues communicated by others". The outcome of looking deeply was seen in theme 1 and theme 3 where students express their feeling of concern towards the people of future generations and holding a strong belief in the democratic approach for making progress towards sustainable development. Theme 1 further highlights the "listening well" component in which students fully focused on Brundtland's definition communicated during the class. Acceptance is about acknowledging one's attitudes and assumptions. Theme 2 and theme 4 are aligned to acceptance because students demonstrate their willingness to care for the environment and commit to sustainable development and assuming that they as engineers (Problem solvers) can bring in change through technology. Finally, Action is about intentional responses based on awareness and acceptance. Theme 5 is mapped to the actions which demonstrate that student's actions are conceived from the awareness and acceptance of sustainable development.

B. The pragmatic implication of results

Based on the observation made in the results section of this study we intend to bring the AAA framework into the sustainable development module. In the upcoming odd semester of the year 2020-21 which will be delivered online using a blended approach (due to the disruption by the COVID19 pandemic), we intend to bring in some changes through the inclusion of new activities and assessment strategies in the sustainable development module to include elements of the acceptance and the action component of the framework. However, the awareness component will be covered through content delivery. The intention behind changing the assessment is to get students to action and also overcome the limitation of this study by grading students for their activities. This leads us to define the future scope of this work in which we aim to implement the AAA framework.

\section{Conclusion}

This paper examined how the sustainable development module has influenced student's values and beliefs in the first year of engineering. The module was able to embed values about the importance of sustainable development and the role of every individual as an engineer and as a citizen towards sustainable development. The concept of carbon footprint had the greatest impact on students which lead them to think and change their actions/behavior to have a sustainable future. Students perceived that their role as an engineer is important through the concept of sustainable leadership matrix and life cycle analysis delivered as a part of this module. Having such values and beliefs embedded in students during their initial (first year) years of engineering education has a potential for high impact as the students carry these values and beliefs to their higher semester of education.

\section{References}

United Nations Educational, Scientific, and Cultural Organization (UNESCO). (2014). UNESCO roadmap for implementing the global action programme on education for sustainable development.

Lehmann, M., Christensen, P., Du, X., \& Thrane, M. (2008). Problemoriented and project-based learning (POPBL) as an innovative learning strategy for sustainable development in engineering education. European journal of engineering education, 33(3), 283-295

Watson, M. K., Noyes, C., \& Rodgers, M. O. (2013). Student perceptions of sustainability education in civil and environmental engineering at the Georgia Institute of Technology. Journal of Professional Issues in Engineering Education and Practice, 139(3), 235-243.

Segalàs, J.; Ferrer-Balas, D.; Mulder, K. F. (2008): Conceptual maps: measuring learning processes of engineering students concerning sustainable development. In European Journal of Engineering Education 33 (3), pp. 297-306. DOI: 10.1080/03043790802088616.

Kemppainen, A. J., Veurink, N. L., \& Hein, G. L. (2007, October) Sustainability in a common first year engineering program. In 2007 37th Annual Frontiers In Education Conference-Global Engineering: Knowledge Without Borders, Opportunities Without Passports (pp. S2J-1). IEEE.Bielefeldt, Angela R. (2011): Incorporating a Sustainability Module into First-Year Courses for Civil and Environmental Engineering Students. In J. Prof. Issues Eng. Educ. Pract. 137 (2), pp. 78-85. DOI: 10.1061/(ASCE)EI.1943-5541.0000050.

Lozano, Francisco J.; Lozano, Rodrigo (2014): Developing the curriculum for a new Bachelor's degree in Engineering for Sustainable Development.
In Journal of Cleaner Production 64, pp. 136-146. DOI: 10.1016/j.jclepro.2013.08.022

Lu, Mingming (2015): Integrating Sustainability into the Introduction of Environmental Engineering. In J. Prof. Issues Eng. Educ. Pract. 141 (2). DOI: 10.1061/(ASCE)EI.1943-5541.0000227.

Rose, Geoffrey; Ryan, Kris; Desha, Cheryl (2015b): Implementing a holistic process for embedding sustainability: a case study in first year engineering, Monash University, Australia. In Journal of Cleaner Production 106, pp. 229-238. DOI: 10.1016/j.jclepro.2015.02.066.

Rose, Geoffrey; Ryan, Kris; Desha, Cheryl (2015a): Implementing a holistic process for embedding sustainability: a case study in first year engineering, Monash University, Australia. Journal of Cleaner Production, 106, 229-238. DOI: 10.1016/J.JCLEPRO.2015.02.066

Kagawa, Fumiyo (2007): Dissonance in student s perceptions of sustainable development and sustainability. In Int J of Sus in Higher Ed 8 (3), pp. 317338. DOI: $10.1108 / 14676370710817174$.

Berglund, Teresa; Gericke, Niklas; Chang Rundgren, Shu-Nu (2014): The implementation of education for sustainable development in Sweden: investigating the sustainability consciousness among upper secondary students. In Research in Science \& Technological Education 32 (3), pp. 318-339. DOI: 10.1080/02635143.2014.944493.

Segalàs, J.; Ferrer-Balas, D.; Mulder, K. F. (2008): Conceptual maps: measuring learning processes of engineering students concerning sustainable development. In European Journal of Engineering Education 33 (3), pp. 297-306. DOI: 10.1080/03043790802088616

Azapagic, A., Perdan, S., \& Shallcross, D. (2005). How much do engineering students know about sustainable development? The findings of an international survey and possible implications for the engineering curriculum. European Journal of Engineering Education, 30(1), 1-19.

Michalos, A. C., Creech, H., Swayze, N., Kahlke, P. M., Buckler, C., \& Rempel, K. (2012). Measuring knowledge, attitudes and behaviours concerning sustainable development among tenth grade students in Manitoba. Social indicators research, 106(2), 213-238.

Watson, M. K., Pelkey, J., Noyes, C., \& Rodgers, M. (2016). Assessing impacts of a learning-cycle-based module on student's conceptual sustainability knowledge using concept maps and surveys. Journal of cleaner production, 133, 544-556.

Fini, Elham H.; Awadallah, Faisal; Parast, Mahour M.; Abu-Lebdeh, Taher (2018): The impact of project-based learning on improving student learning outcomes of sustainability concepts in transportation engineering courses. In European Journal of Engineering Education 43 (3), pp. 473-488. DOI: 10.1080/03043797.2017.1393045

Segalàs, J.; Ferrer-Balas, D.; Mulder, K. F. (2010): What do engineering students learn in sustainability courses? The effect of the pedagogical approach. In Journal of Cleaner Production 18 (3), pp. 275-284. DOI: 10.1016/j.jclepro.2009.09.012.

Baligar, P., Kavale, S., Kaushik, M., Joshi, G., \& Shettar, A. (2018, November). Engineering Exploration: A Collaborative Experience of Designing and Evolving a Freshman Course. In 2018 World Engineering Education Forum-Global Engineering Deans Council (WEEF-GEDC) (pp. 1-5). IEEE.

Creswell, J. W. (2002). Educational research: Planning, conducting, and evaluating quantitative (pp. 146-166). Upper Saddle River, NJ: Prentice Hall.

Carew, A. L.; Mitchell, C. A. (2002): Characterizing undergraduate engineering student`s understanding of sustainability. In European Journal of Engineering Education 27 (4), pp. 349-361. DOI: 10.1080/03043790210166657

Watson, M. K., \& Barrella, E. (2017). Using concept maps to explore the impacts of a learning-cycle-based sustainability module implemented in two institutional contexts. Journal of Professional Issues in Engineering Education and Practice, 143(2), D4016001

Ruiz-Primo; Araceli, Ma: Redalyc.On the Use of Concept Maps as an Assessment Tool in Science: What We Have Learned so far.

Watson, M. K., Pelkey, J., Noyes, C. R., \& Rodgers, M. O. (2016). Assessing conceptual knowledge using three concept map scoring methods. Journal of engineering education, 105(1), 118-146

Watson, M. K., Pelkey, J., Noyes, C. R., \& Rodgers, M. O. (2014, June). Use of concept maps to assess student sustainability knowledge. In 121st ASEE Annual Conference and Exposition. Indianapolis, IN (June 15-18, 2014), American Society of Engineering Education.

Braun, Virginia; Clarke, Victoria (2006): Using thematic analysis in psychology. In Qualitative Research in Psychology 3 (2), pp. 77-101. DOI: 10.1191/1478088706qp063oa.

Abell, N., \& Rutledge, S. E. (2010). Awareness, acceptance and action: developing mindful collaborations in international HIV/AIDS research and service. British Journal of Social Work, 40(2), 656-675.

Rutledge, S. E., \& Abell, N. (2005). Awareness, acceptance, and action: An emerging framework for understanding AIDS stigmatizing attitudes among community leaders in Barbados. AIDS Patient Care \& STDs, 19(3), 186199. 